\title{
Atividades prático-experimentais no ensino de Física ${ }^{+*}$
}

Marcus Vinicius Pereira ${ }^{1}$

Maria Cristina do Amaral Moreira ${ }^{2}$

Programa de Pós-graduação em Ensino de Ciências

Instituto Federal do Rio de Janeiro

Rio de Janeiro - RJ

\section{Resumo}

Neste trabalho, apresentamos uma discussão sobre o papel das atividades prático-experimentais no ensino de física a partir de nossas leituras. Trata-se de uma reflexão sobre essas atividades que são consideradas essenciais a fim de minimizar as dificuldades em aprender e ensinar. Para tal, trouxemos autores que não somente defendem seu uso como também aqueles que são críticos sobre a função pedagógica dessas atividades tal como são realizadas, sobretudo entre os pesquisadores que associam seu uso ao reforço de uma visão ingênua e positivista da ciência. Espera-se, assim, contribuir com uma reflexão crítica dos atores envolvidos com o ensino de física que tenham como objeto de investigação o laboratório didático.

Palavras-chave: Atividade prático-experimental; Laboratório didático; Ensino de Física.

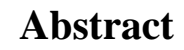

In this paper we present a discussion about the role of practicalexperimental activities in Physics Education from our readings. It is a reflection on those activities that are considered essential in order to minimize difficulties in the learning and teaching processes. Considering this, we brought authors who not only advocate the use as well as those

\footnotetext{
${ }^{+}$Practical-experimental activities in Physics Education

* Recebido: março de 2016. Aceito: setembro de 2016.

${ }^{1}$ E-mail: marcus.pereira@ifrj.edu.br

2 E-mail: maria.amaral@ifrj.edu.br
} 
who are critical of the pedagogical function of these activities as they are carried out, particularly among researchers who associate their use strengthening of a naive and positivist view of science. It is expected, therefore, to contribute to a critical reflection of the actors involved in the Physics Education to have a didactic laboratory as a research object.

Keywords: Practical-experimental activity; Didactic laboratory; Physics Education.

\section{Considerações iniciais}

A história da inserção e da importância atribuída à componente prático-experimental no ensino de ciências, sobretudo no ensino de física, pode ser amplamente encontrada tanto em trabalhos publicados em anais de eventos da área de ensino como em artigos de periódicos que versem sobre o papel do laboratório didático, no contexto nacional e internacional. Trata-se também de um recorrente objeto de investigação de dissertações de mestrado e teses de doutorado. Grandini e Grandini (2004) chamam atenção ao grande número de publicações, entre dissertações, teses e artigos, no período de 1972 e 1992, que se debruçaram sobre os usos do laboratório no ensino de física.

A corrida espacial no final da década de 1950, em plena Guerra Fria, com o lançamento pela União Soviética do primeiro satélite artificial, o Sputnik, em 1957, motivou movimentos de reforma curricular do ensino das ciências naturais. Dessa forma, particularmente nos Estados Unidos, na década de 1960, projetos como o Physical Science Study Committee (PSSC), Harvard e o Biological Science Curriculum Study (BSCS) vieram acompanhados da ênfase na componente prático-experimental para o ensino das ciências naturais como resposta a uma suposta supremacia do ensino de ciências das escolas soviéticas. No caso da física, especificamente, essa componente muito se aproximava de um laboratório científico de cunho experimental, em que o aluno percorreria etapas pré-determinadas na realização de um experimento científico tal como um aprendiz de cientista, fazendo uso "do método científico".

Não demorou muito para que tais projetos de ensino fossem conhecidos internacionalmente e, assim, traduzidos e/ou adaptados para o contexto brasileiro, com destaque, no ensino da física, para os projetos Harvard e PSSC (que requereria professores bem formados e treinados para uso do material sugerido, além de espaço físico dedicado a um laboratório bem equipado). Marcados pela necessidade de reformas e pela relação entre o ensino de ciências e as atividades prático-experimentais, projetos brasileiros foram desenvolvidos e, na década de 1970, surgiram os projetos Física Auto-Instrutiva (FAI) e o Projeto de Ensino de Física (PEF), que enfatizavam um ensino que colocava o aluno em um papel mais ativo, inclusive em relação ao laboratório didático, e não como mero reprodutor de etapas de um roteiro fechado a serem seguidas. 
A necessidade da abordagem prático-experimental no processo de ensino-aprendizagem de uma ciência natural como a física decorre da legitimação da experimentação como a busca por desvelar a natureza, a ciência da experiência. Para Pinho-Alves (2000, p. 175), se para fazer física é preciso do laboratório, então, para aprender física ele também é necessário "a aceitação tácita do laboratório didático no ensino de Física é quase um dogma". A realização de atividades no laboratório didático de física ganha uma conotação de imprescindibilidade, notadamente aceita tanto por professores em todos os níveis, quanto por pesquisadores da área.

Tal necessidade encontra respaldo na prerrogativa de que tais atividades podem facilitar a compreensão de conceitos físicos, além de encorajar a aprendizagem ativa, motivar, despertar o interesse, desenvolver o raciocínio lógico, a comunicação, estimular a capacidade de iniciativa e de trabalho em grupo (HOFSTEIN; LUNETTA, 2004).

No entanto, o questionamento da eficiência do laboratório didático de física, tal como realizado, remonta à mesma época de sua valorização - desde a segunda metade do século XX - quando as pesquisas costumavam apontar o laboratório como um dos grandes potencializadores da melhoria do ensino da física, em que a experimentação por parte do estudante era considerada a salvação para o fracasso, um tipo de "vareta mágica" (COLINVAUX; BARROS, 2002).

\section{Atividade prático-experimental: um termo polissêmico}

Antes da discussão, consideramos necessário esclarecer (e defender) a utilização da expressão atividade prático-experimental, que por se tratar de um termo polissêmico por muitas vezes é considerado como sinônimo de atividade laboratorial, atividade prática, atividade experimental, entre outros.

Segundo Hodson (1992), há certo grau de confusão e de ingenuidade na suposição de que o trabalho prático implica necessariamente o trabalho no laboratório, uma vez que a prática inclui todas as atividades em que o aluno esteja ativamente envolvido, incluindo, portanto, entre outros, o trabalho laboratorial e o trabalho de campo. Esse autor, particularmente, tem sido utilizado nos trabalhos de pesquisa das áreas de ensino de biologia e ensino de ciências. $\mathrm{O}$ trabalho laboratorial requer a utilização de materiais de laboratório, mais ou menos convencionais, podendo ser realizado em um laboratório ou mesmo em uma sala de aula comum (desde que, neste caso, não sejam necessárias condições especiais de segurança, por exemplo).

Dessa forma, trabalho laboratorial não demanda necessariamente o espaço físico de um laboratório, assim como uma atividade nesse contexto de trabalho não necessariamente demanda um trabalho experimental, podendo ser um trabalho prático. Tomemos como primeiro exemplo uma atividade realizada pelo professor em uma sala de aula com a demonstração do experimento de pêndulo simples para determinação da aceleração da gravidade, em que os alunos tomem notas, registrem os dados e procedam com toda a análise do experimento, ou seja, trata-se de um trabalho experimental que não demanda o espaço do laboratório (apesar de autores usarem a expressão atividade laboratorial para esse caso). Agora, cogitemos uma visita a 
um espaço não formal, como um museu, em que haja um pêndulo de Foucault em funcionamento, e o professor aproveite tal momento para a realização de uma atividade com seus estudantes, mas que não necessariamente envolva a medição do comprimento do fio do aparato etc., ou seja, trata-se de uma atividade prática, uma vez que coloca o aluno em um papel mais ativo, reconfigurando o ensino unidirecional focado a partir do professor.

Daí cabe esclarecer a segunda confusão que diz respeito ao termo atividade experimental ou trabalho experimental, como já dissemos, termos também polissêmicos e usados indiscriminadamente na literatura da área de ensino de ciências. O termo "experimental", apesar de não conduzir necessariamente ao trabalho laboratorial, diz respeito a uma atividade que envolve controle e manipulação de variáveis, mesmo que em diferentes níveis. Em resumo, uma atividade de trabalho experimental não implica necessariamente o trabalho laboratorial e viceversa - certas atividades de trabalho prático podem assumir características de trabalho experimental (como no segundo exemplo, de visita a um museu, mencionado anteriormente).

Dessa forma, consideramos, em termos pedagógicos, mais adequada a utilização da expressão atividade prático-experimental para caracterizar as atividades realizadas no contexto de ensino de ciências, uma vez que nesse contexto nem o professor e nem o estudante desempenham o papel de um cientista, tampouco detém de todo o background necessário ao desenvolvimento de um experimento tal como um cientista em seu laboratório. Nessa linha, ressaltase a expectativa de que as atividades prático-experimentais desenvolvam habilidades, cujo objetivo central, remetendo a Nedelsky (1965), pioneiro na discussão sobre o papel do laboratório didático, é que o aluno compreenda a relação entre ciência e natureza. Kirschner (2009) afirma que o professor deve ensinar ciência e ensinar sobre ciência como parte de suas atividades, mas não fazer ciência, confrontando, assim, o próprio Hodson (1988) que indica a necessidade de se contemplar três dimensões no processo de ensino-aprendizagem: aprender ciências, sobre ciências e a fazer ciências.

\section{Discussão}

A realização de atividades prático-experimentais como estratégia didática tem sido apontada por professores e alunos como uma das maneiras mais frutíferas de se minimizar as dificuldades em aprender e ensinar física de modo significativo e consistente (ARAÚJO; ABIB, 2003). Por outro lado, há também os que são críticos sobre a função dessas atividades tal como são realizadas, sobretudo entre os pesquisadores que mostram que, via de regra, elas estão associadas ao reforço de uma visão ingênua e positivista da ciência, que por vezes privilegia o laboratório como espaço de comprovação da teoria, o locus no qual se celebra o que é tratado em sala de aula.

Para se iniciar a discussão sobre o papel das atividades prático-experimentais no ensino de física e a legitimação do laboratório como espaço privilegiado para o seu desenvolvimento, uma ampla revisão da literatura internacional realizada por Lunetta, Hofstein e Clough (2007) sobre o laboratório didático de ciências apresenta as principais metas da aprendizagem a partir 
de atividades realizadas por parte do aluno, como: (i) compreensão conceitual e procedimental (com argumentação a partir dos dados); (ii) conhecimento de como a ciência e o cientista trabalham; (iii) interesse e motivação; (iv) compreensão de métodos de investigação e raciocínio científico, incluindo a natureza da ciência. Esses autores afirmam que tais metas, frequentemente, não são atingidas, o que pode estar associado às competências a serem desenvolvidas pelo professor que, segundo Kirschner (2009), seriam as de ensinar ciência e ensinar sobre ciência e não a de fazer ciência.

Poucos estudos têm investigado a relação entre as atividades prático-experimentais e a aprendizagem em física. Como exemplo, pode-se citar um estudo conduzido em sete países europeus (Dinamarca, Alemanha, França, Inglaterra, Grécia, Itália e Espanha) no final da década de 1990, cuja conclusão não indicou melhoria no ensino de ciências relacionado diretamente ao uso do laboratório didático, mesmo em escolas com condições apropriadas ao ensino prático-experimental como infraestrutura do laboratório/escola, tempo e suporte (ASSOCIATES, 2003). Este estudo identificou que as atividades tendem a se limitar ao trabalho envolvendo instruções precisas de método e análise, fornecidas pelo professor por meio de um roteiro escrito e fechado. Esse levantamento traz ainda algumas recomendações para o laboratório didático, tais como inserção de objetivos epistemológicos, além de objetivos conceituais e procedimentais, e preparação do professor para compreender melhor o que o aluno aprende e pensa quando trabalha com procedimentos e métodos.

Nesse sentido, Borges e Gomes (2005) criticam as atividades que se dão por meio de instruções em um roteiro excessivamente fechado.

O laboratório de ciências pode ser um componente importante para a criação de um ambiente de aprendizagem que contribua para alcançarmos algumas dessas metas curriculares $^{3}$. Porém a forma como as atividades laboratoriais são usualmente estruturadas, com o abuso de roteiros detalhados "tipo receita", impede que possam contribuir para isso (BORGES; GOMES, 2005, p. 73).

Pena e Ribeiro Filho (2009) destacam, fundamentados em vasta literatura, entraves para o uso da experimentação no ensino de física tais como a necessidade de resultados de pesquisa que fundamentem o real papel de atividades prático-experimentais na aprendizagem e a formação do professor para trabalhar com tais atividades, além das condições para seu desenvolvimento, similarmente às recomendações indicadas na pesquisa europeia (ASSOCIATES, 2003).

Outro problema em relação às atividades desenvolvidas no laboratório didático de ciências é a falsa pretensão de atingir um amplo espectro de objetivos em uma mesma sessão de uma aula de laboratório, e que nem sempre são compatíveis com uma única atividade, segundo

\footnotetext{
3 (i) A compreensão dos principais conteúdos da ciência, isto é, o conhecimento de modelos, ideias e teorias fundamentais para a formação de uma cultura científica; (ii) A compreensão dos métodos de investigação usados nas ciências; (iii) A compreensão da ciência enquanto um empreendimento social. (MILLAR, 1996 apud BORGES; GOMES, 2005, p.72).
} 
Tamir (1991). Para esse autor, o planejamento de uma determinada atividade prático-experimental poderia desenvolver algumas habilidades específicas em cada sessão.

Hofstein, Shore e Kipnis (2004) afirmam que a pesquisa ainda não foi capaz de evidenciar as relações entre as atividades desenvolvidas no laboratório e a aprendizagem dos estudantes. Para Singer, Hilton e Schweingruber (2005), por vezes essas atividades são independentes do fluxo de ensino e são focadas mais em procedimentos do que na produção de significados para colaborar com a construção dos conceitos científicos trabalhados em aula. Corroborando os autores acima, os resultados da pesquisa conduzida por Maltese, Tai e Sadler (2010) mostraram que quanto mais tempo os estudantes permanecem focados em procedimentos de laboratório, menor é o desempenho dos mesmos, enquanto os poucos estudantes que relataram ter professores no ensino médio que, de alguma forma, relacionavam as atividades prático-experimentais com fenômenos do mundo real, tiveram desempenho significativamente melhor.

O importante não é a manipulação de objetos e artefatos concretos, e sim o envolvimento comprometido com a busca de respostas/soluções bem articuladas para as questões colocadas, em atividades que podem ser puramente de pensamento. [...] Atividades de resolução de problemas, modelamento e representação, com simulações em computador, desenhos, pinturas, colagens ou simplesmente atividades de encenação e teatro, cumprem esse papel de mobilizar o envolvimento do aprendiz. Essas atividades apresentam, muitas vezes, vantagens claras sobre o laboratório usual, uma vez que não requerem a simples manipulação, às vezes repetitiva e irrefletida, de objetos concretos, mas de ideias e representações, com o propósito de comunicar outras ideias e percepções (BORGES, 2002, p. 295).

Para Hodson (1994), apesar do apoio dos professores, pouco se investiga sobre a relação entre experimentação e aprendizagem, bem como o problema acarretado pelo investimento de tempo, energia e de recursos para tal. A reflexão crítica do autor sobre essa questão o levou à conclusão de que não se pode garantir que a atividade prático-experimental, do ponto de vista didático, seja melhor que outras metodologias de ensino, tais como o uso de simulações computacionais, recursos audiovisuais, experiências de pensamento etc.

Na realidade brasileira, os estudantes, quando têm aulas de laboratório, normalmente fazem uso de roteiros fechados, devendo seguir procedimentos determinados, medir e relatar resultados, não sendo, assim, capacitados a demonstrar ou construir os objetos envolvidos na atividade, nem explorar relações, testar previsões ou selecionar entre duas ou mais explicações para o fenômeno.

Mesmo nos países onde a tradição de ensino experimental está bem sedimentada, a função que o laboratório pode e deve ter, bem como a sua eficácia em promover as aprendizagens desejadas, têm sido objeto de questionamentos, o que contribui para manter a discussão sobre a questão há alguns anos (BORGES, 2002, p. 13). 
Laburú, Barros e Kanbach (2007, p. 306) listam, mais detalhadamente, possíveis justificativas para a rara utilização de atividades prático-experimentais no ensino médio, salientando que as explicações dos professores de física do ensino médio para a resistência em utilizar tais atividades em suas aulas se deve, por exemplo, à

\begin{abstract}
indisponibilidade ou qualidade de material, excessivo número de alunos em sala de aula, formação precária dos professores, pouca bibliografia para orientá-los, restrições institucionais, como falta de tempo para as aulas, disponibilidade da sala de laboratório [...] quando se precisa (Tsai, 2003: 855), ausência de horário específico na programação, necessidade de laboratorista, inexistência de programação e articulação entre atividades experimentais com o curso (RICHOUX \& BEAUFILS 2003; GARCIA et al., 1995), falta de atividades preparadas, ausência de tempo para o professor planejar e montar suas atividades, carência de recurso para a compra e substituição de equipamentos e de materiais de reposição (BORGES 2000; PESSOA et al., 1985).
\end{abstract}

Por outro lado, o primeiro entrave apontado por Villani e Carvalho (1993, p. 75), ainda atual apesar de remontar mais de 20 anos, pode ajudar a refletir sobre algumas das dificuldades dos estudantes ao trabalharem no laboratório didático, bem como os seus efeitos, que permanecem ainda sem uma definição clara.

\begin{abstract}
Apesar de estarem convencidos da importância das atividades experimentais, os docentes que as utilizam abundantemente em sua prática didática têm consciência de que a experimentação está longe de constituir a panaceia para o ensino de Física; a aprendizagem dos estudantes parece sujeita a limitações e ambiguidades, que tornam o problema digno de ser analisado mais cuidadosamente.
\end{abstract}

Apesar do discurso dos professores sobre a importância da presença do laboratório no ensino da física, não há tradição escolar em utilizar de fato atividades prático-experimentais (PINHO-ALVES, 2000), seja pela falta de clareza que se tem hoje quanto ao papel do laboratório no processo de ensino-aprendizagem, seja pela mobilização de um amplo espectro de habilidades por parte dos estudantes e também dos professores, como montagem do experimento, compreensão dos conceitos físicos trabalhados, utilização de instrumentos de medida, obtenção, registro e análise de dados, entre outros. Essas habilidades requerem maturação, assim como uma infraestrutura física e didática que exigem do professor organização e disponibilidade para seu desenvolvimento, especialmente quando ele não é dedicado exclusivamente às aulas de laboratório, fato comum em grande parte das escolas brasileiras, e ainda mais quando precisa trabalhar em mais de uma escola e com condições cada vez mais desfavoráveis.

Para entender essa falta de compreensão dos objetivos do laboratório didático de física, é preciso caracterizar as diferentes formas de se fazer atividades neste espaço. Tamir (1991) identificava três tipos distintos de atividades práticas: experiências, que aproximam o aluno da 
fenomenologia; exercícios com a finalidade de desenvolver habilidades práticas e técnicas; investigações, em que os alunos têm maior abertura para a resolução de problemas, testar ideias e elaborar explicações para os fenômenos. Araújo e Abib (2003, p. 177), de uma maneira mais simples e atual, identificam os usos de atividades prático-experimentais no ensino:

A análise do papel das atividades experimentais desenvolvidas amplamente nas últi-
mas décadas revela que há uma variedade significativa de possibilidades e tendências
de uso dessa estratégia de ensino de Física, de modo que essas atividades podem ser
concebidas desde situações que focalizam a mera verificação de leis e teorias, até
situações que privilegiam as condições para os alunos refletirem e reverem suas
ideias a respeito dos fenômenos e conceitos abordados, podendo atingir um nível de
aprendizado que lhes permita efetuar uma reestruturação de seus modelos explicati-
vos dos fenômenos (ARAÚJO; ABIB, 2003, p. 177).

A citação acima nos permite refletir sobre a amplitude epistemológica envolvendo atividades prático-experimentais, compreendendo desde uma visão empirista-indutivista, segundo a qual atividades são realizadas para comprovação da teoria aprendida em sala de aula, sobretudo na tentativa de se chegar à teoria a partir da empiria, até uma visão dedutivista-racionalista, segundo a qual os estudantes alcançam uma melhor compreensão da natureza da ciência e/ou uma visão da ciência como prática social, para além de uma ciência neutra como um acúmulo de fatos e um conjunto de verdades absolutas.

Arruda e Laburú (1998), ao discutirem questões epistemológicas nas considerações sobre o papel das atividades prático-experimentais no ensino de ciências, tanto em livros didáticos como a partir da concepção de professores de ciências ou mesmo de cientistas, afirmam que a imagem de ciência restringe-se a uma ideia tradicional ou popular: leis e/ou teorias científicas se encontram na natureza e podem ser descobertas pela investigação científica, ou seja, por meio da observação sistemática, da aplicação do "método científico", como se este fosse único e sempre válido. Os autores trazem à tona a concepção baseada no senso comum segundo a qual a função da atividade prático-experimental na ciência é comprovar hipóteses ou validar teorias, que, a partir de então, podem ser chamadas de "leis" e consideradas "verdadeiras" (ARRUDA e LABURÚ, 1998), concepção essa muitas vezes refletida nas aulas de laboratório de física do ensino médio.

A crítica, cerne da epistemologia, só será desenvolvida pelos alunos se tiverem oportunidade efetiva de experimentar, testar, pôr a prova, tentar convencer pelo argumento, que é o que um ensino experimental efetivo proporciona. E neste processo de construção o professor é um "epistemólogo auxiliar” dos seus alunos, que pela crítica também vai mostrando caminhos como possibilidades (RAMOS, 2003, p.32).

Por fim, para refletir para além do conhecimento científico que teria um fim em si mesmo, para além da ciência como detentora de verdades absolutas, a realização de atividades 
prático-experimentais pode ser entendida como uma estratégia didática que facilitaria a compreensão da ciência mutável, em construção, reflexo da produção humana.

Nesse sentido, Rosito (2003, p. 208) destaca que

boas atividades experimentais se fundamentam na solução de problemas, envolvendo questões da realidade dos alunos, que possam ser submetidas a conflitos cognitivos. Desta forma, o ensino de Ciências, integrando teoria e prática, poderá proporcionar uma visão das ciências como uma atividade complexa, construída socialmente, em que não existe um método universal para solução de todos os problemas, mas uma atividade dinâmica, interativa, uma constante interação de pensamento e ação.

As investigações realizadas nos últimos anos parecem ir em direção à constatação de uma contribuição escassa da experimentação para o ensino de física. É necessário propiciar que o trabalho do aluno no laboratório didático valorize a criatividade que por vezes permeia o próprio fazer científico ao mesmo tempo em que instigue desafios cognitivos, se afastando, com isso, da ideia de produção de verdades absolutas e inquestionáveis que traduzem uma visão de ciência neutra.

Algumas críticas feitas às atividades práticas no ensino de Ciências se referem ao fato de que a maior parte do tempo é consumida na montagem e coleta de dados, restando pouco tempo para a análise, discussão dos resultados e ao próprio entendimento da atividade realizada (SIAS; TEIXEIRA, 2006, p. 361).

Saraiva-Neves, Caballero e Moreira (2006, p.388) atribuem isso ao modo tradicional como são realizadas atividades no laboratório didático de física, chegando a afirmar ser contraproducente na construção do conhecimento dos alunos quando uma atividade tem caráter

meramente ilustrativo, resumindo-se a experiências do tipo "receita", apresentando sérias deficiências (GARCIA BARROS, S. et al., 1995), gerando pouca motivação nos alunos (BARBERÁ; VALDÉS, 1996) e favorecendo um tipo muito limitado de competências (HODSON, 1990).

No entanto, apesar de combatidas tanto por alguns professores como pela maioria dos pesquisadores em ensino, as atividades do tipo "receita" são justamente as mais realizadas tanto no ensino médio como no ensino superior, provavelmente derivadas de uma postura equivocada quanto à natureza da ciência.

\section{Considerações finais}

Há falta de ressonância entre o que se pensa e a prática pedagógica do laboratório didático de física, uma vez que muitos professores, quando indagados, alegam fazer uso e/ou considerar indispensáveis atividades prático-experimentais em suas aulas, mesmo não sendo bem compreendido o seu papel no processo de ensino e de aprendizagem. É preciso ter cuidado 
neste sentido. Não se propõe, de forma alguma, o abandono do trabalho prático-experimental, muito pelo contrário, as argumentações apresentadas levam à preocupação quanto à possibilidade de trabalhar atividades prático-experimentais de uma forma holística, que permita ampla exploração do fenômeno físico.

O caráter investigativo e problematizador de atividades práticas pode viabilizar a relação entre aspectos teóricos e empíricos e facilitar, por exemplo, o domínio da linguagem científica (um dos objetivos do ensino médio no Brasil segundo documentos oficiais nas diversas esferas). O laboratório didático é um espaço importante na escola para apropriação, consolidação e aprimoramento dos conceitos científicos, e consideramos como saldo positivo o resultado do debate entre defesa e questionamento do seu papel, ou melhor, papeis, uma vez que o laboratório didático foi alvo de pesquisas em ensino sob diferentes enfoques, sendo impossível associar a ele um único papel: "as potencialidades e funções do laboratório suscitam muitas reflexões e controvérsias, posto que seu papel sempre será uma questão polêmica para o ensino de ciências" (LABURÚ; SILVA, 2011, p. 723). Chamamos atenção que a tentativa de aproximação entre o caráter investigativo e as atividades prático-experimentais pode esbarrar em uma situação: a compreensão dos próprios alunos acerca do papel do professor e das atividades, que, em geral, estão acostumados com um ensino diretivo e não muito aberto.

No momento em que o display flexível não se encontra em um futuro tão distante, e TV, celular, computador e videogame estão cada vez mais integrados entre si e à rede mundial de computadores, a escola e as mudanças tecnológicas devem estreitar relações no sentido de fazer com que as atividades prático-experimentais desempenhem funções sociais relevantes para os estudantes ao estarem vinculadas de fato a um projeto educacional. Por outro lado, a grande quantidade de recursos construídos com propósito educativo em forma digital, como animações, simulações, softwares e vídeos (muitos deles disponíveis na internet), cria expectativa quanto ao uso da informática como solução dos problemas que afligem o ensino - a "vareta mágica" da educação no século XXI, tal como o laboratório foi considerado na segunda metade do século passado.

Não menos importante, há de se considerar o processo de formação de professores que, muitas vezes, não inclui essa discussão e visa a atender a prerrogativa da transmissão de conhecimento, formando profissionais que valorizam os conteúdos acima de tudo, que priorizam um modelo de aula expositiva, mesmo quando incorporam atividades prático-experimentais, em que não há espaço (e tempo) para se pensar formas alternativas de ensinar e aprender.

\section{Agradecimento}

Os autores agradecem aos pareceristas pelas contribuições fundamentais dadas a este trabalho. 


\section{Referências}

ARAÚJO, M. S.; ABIB, M. L. V. S. Atividades experimentais no ensino de física: diferentes enfoques, diferentes finalidades. Revista Brasileira de Ensino de Física, v. 25, n. 2, p.176194, 2003.

ARRUDA, S. M.; LABURÚ, C. E. Considerações sobre a função do experimento no ensino de ciências. In: NARDI, R. (Org.). Questões atuais no ensino de ciências. São Paulo: Escrituras, 1998, p. 53-60.

ASSOCIATES, PJB. Briefing Paper 4 - Labwork in science education. 2003. In: New Perspectives for Learning. Disponível em: 〈http://www.pjb.co.uk/npl/bp4a.pdf〉. Acesso em: 10 fev. 2016.

BORGES, A. T. Novos rumos para o laboratório escolar de ciências. Caderno Brasileiro de Ensino de Física, v. 19, n. 3, p. 291-343, 2002.

BORGES, A. T.; GOMES, A. D. T. Percepção de estudantes sobre desenhos de testes experimentais. Caderno Brasileiro de Ensino de Física, v. 22, n. 1, p. 71-94, 2005.

COLINVAUX, D.; BARROS, S. S. O papel da modelagem no laboratório didático de Física: o que há para se aprender? In: ENCONTRO DE PESQUISA EM ENSINO DE FÍSICA, 8, 2002, Águas de Lindóia. Anais... São Paulo: SBF, 2002.

GRANDINI, N. A.; GRANDINI, C. R. Os objetivos do laboratório didático na visão dos alunos do curso de licenciatura em física da UNESP-Bauru. Revista Brasileira de Ensino de Física, v. 26, n. 3, p. 251-256, 2004.

HODSON, D. Hacia un enfoque más crítico del trabajo de laboratorio. Enseñanza de las Ciencias, v. 12, n. 3, p. 299-313, 1994.

Redefining and reorienting practical work in school science. School Science Review, v. 73, p. 65-78, 1992.

. Toward a philosophically more valid science curriculum. Science Education, v. 72, n. 1, p. 19-40, 1988.

HOFSTEIN, A.; LUNETTA, V. N. The laboratory in science education: foundations for the twenty-first century. Science Education, v. 88, n. 1, p. 28-54, 2004.

HOFSTEIN, A.; SHORE, R.; KIPNIS, M. Providing high school chemistry students with opportunities to develop learning skills in an inquiry-type laboratory: a case study. International Journal of Science Education, v. 26, n. 1, 2004. 
KIRSCHNER. P. Epistemology or Pedagogy, that is the question. In: DUFFY, T. M.; TOBIAS, S. (Eds.) Constructivism Instruction: success or failure? New York: Routledge, 2009. cap. 8, p. 144-157.

LABURÚ, C. E.; BARROS, M. A.; KANBACH, B. G. A relação com o saber profissional do professor de física e o fracasso da implementação de atividades experimentais no ensino médio. Investigações em Ensino de Ciências, v. 12, n. 3, p. 305-320, 2007.

LABURÚ, C. E.; SILVA, O. H. M. O laboratório didático a partir da perspectiva da multimodalidade representacional. Ciência \& Educação, v. 17, n. 3, p. 721-734, 2011.

LUNETTA, V. N.; HOFSTEIN; A.; CLOUGH, M. P. Learning and teaching in the school science laboratory: an analysis of research, theory, and practice. In: ABELL, S. K.; LEDERMAN, N. G. (Eds.) Handbook of Research in Science Education. New Jersey: Routledge, 2007. cap. 15 , p. 393-441.

MALTESE, A. V.; TAI, R. H.; SADLER, P. M. The effect of High School physics laboratories on performance in introductory College Physics. The Physics Teacher, v. 48, n. 333, 2010.

NEDELSKY, L. Science Teaching and Testing. New York: Harcourt, Brace \& World Inc., 1965.

PENA, F. L. A.; RIBEIRO FILHO, A. Obstáculos para o uso da experimentação no ensino de física: um estudo a partir de relatos de experiências pedagógicas brasileiras publicados em periódicos nacionais da área (1971-2006). Revista Brasileira de Pesquisa em Educação em Ciências, v. 9, n. 1, 2009.

PINHO-ALVES, J. Regras da transposição didática aplicadas ao laboratório didático. Caderno Brasileiro de Ensino de Física, v. 17, n. 2, p. 174-188, 2000.

RAMOS, M. G. Epistemologia e Ensino de Ciências: compreensões e perspectivas. In: MORAES, R. (Org). Construtivismo e ensino de ciências: reflexões epistemológicas e metodológicas. Porto Alegre: EDIPUCRS. 2. ed. 2003. p.13-35.

ROSITO, B. A. O ensino de ciências e a experimentação. In: MORAES, R. (Org.). Construtivismo e Ensino de Ciências: reflexões epistemológicas e metodológicas. Porto Alegre: EDIPUCRS. 2. ed. 2003. p.195-208.

SARAIVA-NEVES, M.; CABALLERO. C.; MOREIRA, M. A. Repensando o papel do trabalho experimental, na aprendizagem da física em sala de aula - um estudo exploratório. Investigações em Ensino de Ciências, v. 11, n. 3, p. 383-401, 2006.

SIAS, D. B.; TEIXEIRA, R. M. R. Resfriamento de um corpo: a aquisição automática de dados propiciando discussões conceituais no laboratório didático de Física no Ensino Médio. Caderno Brasileiro de Ensino de Física, v. 23, n. 3, p. 360-381, 2006. 
SINGER, S. R.; HILTON, M. L.; SCHWEINGRUBER, H. A. Needing a new approach to science labs. Science Teacher, v. 72, n. 10, 2005.

TAMIR, P. Practical work in school science: an analysis of current practice. In: WOOLNOUGH, B. E. (Ed.). Practical Science: the role and reality of practical work in school science. Milton Keyes: Open University Press, 1991. p. 13-20.

VILLANI, A.; CARVALHO, L. O. Representações mentais e experimentos qualitativos. Revista Brasileira de Ensino de Física, v. 15, n. 1 a 4, p. 74-89, 1993. 